\title{
Anti-Apoptotic Pathways in Bone Marrow and Megakaryocytes in Myeloproliferative Neoplasia
}

\author{
Suzanne M. Koopmans ${ }^{\mathrm{a}}$ Harry C. Schouten ${ }^{\mathrm{b}}$ Arienne M.W. van Marion ${ }^{\mathrm{c}}$ \\ ${ }^{a}$ Department of Pathology and ${ }^{b}$ Division of Hematology, Department of Internal Medicine, Maastricht University \\ Medical Center, Maastricht, and ' $\mathrm{Department}$ of Pathology, VieCuri Medical Center, Venlo, The Netherlands
}

\section{Key Words}

Anti-apoptotic pathways · Bnip3 · Erk signaling ·

Microvessel density · Myeloproliferative neoplasia ·

PI3K-Akt signaling

\begin{abstract}
Objective: Proliferative activity contributes to bone marrow cellularity in myeloproliferative neoplasia (MPN). Megakaryocytes are the most important cells in MPN bone marrow pathology. JAK2 ${ }^{\mathrm{V} 617 F}$ mutation constitutively activates JAK2, pErk (phosphorylating extracellular signal-regulated kinase) and PI3K (phosphatidylinositol 3-kinase)-Akt signaling. Erk is involved in megakaryocyte differentiation, PI3K-Akt inhibits megakaryocyte apoptosis via $\mathrm{BCl}-\mathrm{x}_{\mathrm{L}}$ and two downstream effectors (p70S6k and Bnip3). Immunohistochemic expression of phosphorylated Erk, Akt, p70S6k and Bnip3 was studied along with microvessel density (MVD) in MPN bone marrow and megakaryocytes. Methods: 36 essential thrombocythemia (ET), 25 polycythemia vera and 45 primary myelofibrosis patients were analyzed for pErk, pAkt, Bnip3, p70S6k and MVD expression by immunostaining bone marrow biopsy sections followed by automated image analysis. JAK2 ${ }^{V 617 F}$ was analyzed through real-time PCR in blood samples. $\boldsymbol{R e}$ sults: pErk and pAkt were significantly higher expressed in MPN megakaryocytes, mainly in ET patients, compared to controls. Bnip3 was higher expressed in bone marrow of control patients and in MPN megakaryocytes. Mainly in
\end{abstract}

\section{KARGER}

E-Mail karger@karger.com

www.karger.com/pat
ET patients, MPN megakaryocytes showed higher p70S6k expression compared to controls. Conclusion: Increased bone marrow cellularity in MPN patients might be influenced by increased pErk, pAkt and decreased Bnip3 expression. A dominant role for megakaryocytes in ET patients was shown. Increased amounts of megakaryocytes in MPN patients can be due to increased pAkt and p70S6k.

C 2013 S. Karger AG, Basel

\section{Introduction}

Myeloproliferative neoplasias (MPN) are clonal bone marrow stem cell disorders originating from a multipotent hematopoietic stem cell characterized by proliferation of myeloid, erythroid and/or megakaryocytic cell lineages resulting in increased numbers of granulocytes, erythrocytes or platelets in the peripheral blood.

MPNs can be divided into chronic myelogenous leukemia carrying the Philadelphia $(\mathrm{Ph}+)$ chromosome as a result of $\mathrm{t}(9 ; 22)$ and diseases which do not carry the Philadelphia chromosome ( $\mathrm{Ph}-$ ) [1]. The three most commonly occurring classical $\mathrm{Ph}-\mathrm{MPN}$ are essential thrombocythemia (ET), polycythemia vera (PV) and primary myelofibrosis (PMF) [2, 3].

In 2005, a mutation in the JAK2 gene was detected. The $J A K 2^{V 617 F}$ mutation, which substitutes valine for phenylalanine and disrupts the inhibitory function of the 
Table 1. Clinical and laboratory findings of the patients with ET, PV and PMF and the control group

\begin{tabular}{|c|c|c|c|c|}
\hline Males/females & $11 / 25$ & $8 / 17$ & $26 / 19$ & $23 / 13$ \\
\hline Age, years & $59 \pm 17.70$ & $65 \pm 13.56$ & $67 \pm 10.73$ & $56 \pm 14.33$ \\
\hline JAK2: wild type/mutation/unknown & $15 / 19 / 2$ & $2 / 17 / 6$ & $7 / 20 / 18$ & $36 / 0 / 0$ \\
\hline White blood cell count, $\times 10^{9} / 1$ & $9.37 \pm 2.89$ & $16.08 \pm 12.22$ & $11.89 \pm 11.38$ & $8.16 \pm 4.44$ \\
\hline Range & $4.4-18.30$ & $5.70-62.00$ & $0.90-70.60$ & $2.80-23.80$ \\
\hline Hematocrit, $1 / 1$ & $0.43 \pm 0.06$ & $0.52 \pm 0.09$ & $0.35 \pm 0.08$ & $0.39 \pm 0.05$ \\
\hline Range & $0.29-0.61$ & $0.37-0.68$ & $0.15-0.50$ & $0.30-0.52$ \\
\hline Thrombocytes, $\times 10^{9} / 1$ & $929 \pm 346$ & $662 \pm 316$ & $564 \pm 532$ & $263 \pm 137$ \\
\hline Range & $327-1,862$ & $112-1,371$ & $15-2,644$ & $49-585$ \\
\hline
\end{tabular}

Means $\pm \mathrm{SD}$, numbers and ranges are shown.

pseudokinase domain in JAK2, constitutively activates the JAK2 gene [4-7]. The activating JAK2 ${ }^{V 617 F}$ mutation is involved in several different pathways: in the mitogenactivated protein kinase (MAPK) signaling pathway, PI3K (phosphatidylinositol 3-kinase)-Akt signaling pathway and the activation of the STAT (signal transducer and activator of transcription) family $[5,8]$. Besides pathways influenced by the mutated JAK2 gene, in general both pro- and anti-apoptotic proteins could be involved in the pathogenesis of $\mathrm{Ph}-\mathrm{MPN}$.

First, JAK2 can activate the receptor tyrosine kinaseGrb2-SOS signaling axis, activating Ras GTPase and Raf and then MEK and Erk (extracellular signal-regulated kinase) signaling. The Erk signaling pathway is not only activated by JAK 2 but can also be activated by numerous extracellular signals [8-10]. Several studies have shown the involvement of the Erk pathway in megakaryocyte differentiation [11-13]. Therefore, we examined the phosphorylation status of Erk (pErk) in bone marrow trephines of $\mathrm{Ph}-\mathrm{MPN}$ patients and in megakaryocytes.

Second, the PI3K-Akt signaling pathway is activated by the JAK2 mutation. Akt is an important mediator in the PI3K pathway and is involved in many cellular processes, including inhibition of apoptosis, protein synthesis and cell differentiation and metabolism. It is already known that Akt is constitutively activated in acute myeloid leukemia [14-18]. The PI3K-Akt pathway is activated by growth factors and cytokines resulting in phosphorylation of Akt, which up-regulates $\mathrm{Bcl}-\mathrm{x}_{\mathrm{L}}$ leading to inhibition of megakaryocyte apoptosis [19]. The mammalian target of rapamycin (mTor) is a serine/threonine kinase which is an effector protein of Akt [20]. Akt and mTor are both necessary for the activation of ribosomal
p70S6 kinase (p70S6k) [21]. Therefore, we also examined the phosphorylation status of Akt (pAkt) and p70S6k in bone marrow trephines of $\mathrm{Ph}-\mathrm{MPN}$ patients.

Third, besides the Akt signaling pathway, anti-apoptotic proteins could also be important factors in the development of $\mathrm{Ph}-\mathrm{MPN}$. The Bcl-2 protein family consists of both proand anti-apoptotic proteins, depending on the different combinations of the Bcl-2 homology domains. Bnip3 is a pro-apoptotic protein belonging to the Bcl-2 family. Bnip3 is activated under hypoxic conditions in normal and cancer tissue upon hypoxia-inducible factor (Hif-1a) [22-24].

In the present study, we investigated the Erk and PI3KAkt pathway and the expression of Bnip3 and p70S6k along with microvessel density (MVD) by immunohistochemistry on trephine biopsies to characterize abnormal activation of these pathways and abnormal apoptotic responses in bone marrow and megakaryocytes of $\mathrm{Ph}-\mathrm{MPN}$ patients.

\section{Design and Methods}

Study Population

The study was carried out on bone marrow trephines obtained from patients recorded at the Maastricht University Medical Center, Maastricht, between January 1992 and December 2009, at the Haga Hospital, The Hague, between January 2006 and December 2009 and at the VieCuri Medical Centre, Venlo, between January 2005 and July 2010. The study was approved by the local institutional ethics committees. The study population consisted of 106 patients with a myeloproliferative neoplasm, with a mean age of 63.6 years $(\mathrm{SD} \pm$ 14.7 , ranging from 17 to 86 years) at the time of diagnosis. None of the patients received therapy when the biopsy was taken. The patient population included in the study consisted of $36 \mathrm{ET}$ (33.9\%), 25 PV (23.6\%) and 45 PMF (42.5\%) patients. All patients were clinically and histologically diagnosed according to the World Health Organization classification of 2008 [25]. As shown in tables 1 and 2, 
Table 2. Clinical and laboratory findings of patients with the JAK2 mutation or with wild-type JAK2

\begin{tabular}{lcc}
\hline & $\begin{array}{l}\text { JAK2 positive } \\
(\mathrm{n}=56)\end{array}$ & $\begin{array}{l}\text { Wild-type JAK2 } \\
(\mathrm{n}=24)\end{array}$ \\
\hline Males/females & $26 / 30$ & $9 / 15$ \\
Age, years & $64 \pm 14.96$ & $63 \pm 14.28$ \\
White blood cell count, $\times 10^{9} / 1$ & $13.6 \pm 9.64$ & $8.5 \pm 3.76$ \\
Hemoglobin, mmol/1 & $8.91 \pm 1.46$ & $7.81 \pm 1.67$ \\
Hematocrit, $1 / 1$ & $0.44 \pm 0.08$ & $0.39 \pm 0.09$ \\
Thrombocytes, $\times 10^{9} / 1$ & $728 \pm 341$ & $907 \pm 374$ \\
\hline
\end{tabular}

Means \pm SD except for the number of males/females.

61 patients $(57.5 \%)$ were women and $45(42.5 \%)$ were men. Fifty-six patients were carriers of the JAK2 ${ }^{V 617 F}$ mutation (19 ET, $17 \mathrm{PV}$ and 20 PMF patients), 24 patients were carriers of the JAK2 wild-type gene (15 ET, $2 \mathrm{PV}$ and 7 PMF patients) and in 26 patients the $J A K 2^{V 617 F}$ mutation status was unknown due to insufficient DNA to detect the JAK2 status by PCR and because patients died prior to the availability of the $J A K 2^{V 617 F}$ mutation test.

The patients were subdivided for the grading of myelofibrosis (mf) into $\mathrm{mf} 0 / 1$ and $\mathrm{mf} 2 / 3 ; 43$ patients belonged to the $\mathrm{mf} 0 / 1$ group (19 ET, $12 \mathrm{PV}$ and $12 \mathrm{PMF}$ ), of which 24 were $J A K 2^{V 617 F}$ positive and 11 JAK2 wild type; 61 belonged to the $\mathrm{mf} 2 / 3$ group (17 ET, $12 \mathrm{PV}$ and $32 \mathrm{PMF}$ ), of which 31 were $J A K 2^{V 617 F}$ positive and $13 \mathrm{JAK} 2$ wild type.

The control group consisted of 36 morphologically normal negative staging biopsies from patients with non-Hodgkin lymphoma and Hodgkin lymphoma (mean age: 55.8 years).

\section{Immunohistochemistry}

The bone marrow biopsy specimens were decalcified using the Kristensen procedure for $1 \mathrm{~h}$ or EDTA decalcification for $4 \mathrm{~h}$, followed by standard tissue processing and paraffin embedding. From the paraffin-embedded blocks, $3-\mu \mathrm{m}$ sections were cut for immunohistochemical staining and mounted on StarFrost slides (Knittel Gläser, Braunschweig, Germany). All the antibodies were tested for specificity on positive and negative tumor control slides and also individually tested on decalcified control bone marrow biopsies, resulting in a variation of immunohistochemical techniques optimized for all individual antibodies.

Immunohistochemical staining of pErk, pAkt, Bnip3 and p70S6k was carried out using the antihuman rabbit monoclonal antibody phospho-p44/42MAPK ( $\mathrm{Thr}^{202} / \mathrm{Tyr}^{204}$ ), phospho-Akt $\left(\mathrm{Ser}^{473}\right)$, antihuman mouse monoclonal antibody anti-Bnip3 (B7931) and phospho-70S6 kinase $\left(\mathrm{Thr}^{389} ; 1 \mathrm{~A} 5\right)$ at a dilution of 1 : $100,1: 25,1: 300$ and 1:100, respectively [pErk, pAkt and p70S6k (Cell Signaling Technology, Danvers, Mass., USA) and Bnip3 (Sigma-Aldrich, St. Louis, Mo., USA)]. After deparaffinization, the slides were put in $0.3 \% \mathrm{H}_{2} \mathrm{O}_{2}$ (Bnip3, p70S6k) in methanol to block endogenous peroxidase activity, followed by antigen retrieval by boiling for $20 \mathrm{~min}$ in $10 \mathrm{mM}$ sodium citrate buffer $(\mathrm{pH}$ 6.0) in a water bath of $100^{\circ} \mathrm{C}$. For pErk and pAkt after deparaffinization and antigen retrieval by boiling for $20 \mathrm{~min}$ in $10 \mathrm{mM}$ sodium citrate buffer ( $\mathrm{pH} 6.0$ ) in a water bath at $100^{\circ} \mathrm{C}$, endogenous peroxidase activity was blocked in $3 \% \mathrm{H}_{2} \mathrm{O}_{2}$ in methanol.
After blocking solution [3\% BSA/PBS for Bnip3 and p70S6k and TBST (Tris-buffered saline Tween)/5\% goat serum ( $\mathrm{pH} 7.2-7.6)$ for pErk and pAkt], the primary antibody, applied in TBST/1\% BSA (pH 7.2-7.6 for pErk, pAkt) or antibody diluent (for Bnip3, p70S6k; Dako, Glostrup, Denmark) was incubated overnight at $4^{\circ} \mathrm{C}$ (pErk, pAkt) or for $1 \mathrm{~h}$ at room temperature (Bnip3, p70S6k). The slides were then incubated for $30 \mathrm{~min}$ with a PowerVision poly-HRP-anti Ms/Rb/Ra IgG histostaining kit (ImmunoLogic, Duiven, The Netherlands: pErk, pAkt) or with EnVision [Dako Real $^{\mathrm{TM}}$ EnVision ${ }^{\mathrm{TM}}$ detection system (K5007); Bnip3, p70S6k]. After developing the color with freshly made diaminobenzidine solution (Dako), slides were counterstained with hematoxylin (Merck, Whitehouse Station, N.J., USA), dehydrated and mounted in Entellan (Merck).

The 142 trephines (MPN patients plus control patients) were immunohistochemically analyzed using an automated immunostainer (Dako Autostainer Link 48) with CD34 (clone QBend 10; Dako). CD34 was incubated for $20 \mathrm{~min}$ at room temperature. The reaction was revealed by means of the Dako EnVision Flex Kit (Dako) according to the manufacturer's instructions.

\section{Quantification of Staining}

The numbers of cells staining positive for pErk, pAkt, Bnip3 and p70S6k (fig. 1) were quantified using an image processing and analysis system (Leica, Cambridge, UK) linked to a Leica DML3000 light microscope (Leica Quantimet). The program used in this system was QWin (Leica's Windows-based image analysis tool kit). All measurements were conducted at $\times 40$ magnification pictures. For measuring pErk, pAkt, Bnip 3 and p70S6k, 5 hot spots per slide were included to measure total tissue, total nuclei positive for $\mathrm{pErk}$, pAkt, Bnip3 or p70S6k and total nuclear count. The amount of positivity was calculated as the percentage of positive nuclear pixels related to the total number of nuclear pixels.

From the 5 pictures taken, we counted the total amount of megakaryocytes, the total amount of positively stained megakaryocytes, and megakaryocytes with nuclear and cytoplasmic staining. The mean total amounts of megakaryocytes, positively stained megakaryocytes, and megakaryocytes with nuclear and cytoplasmic staining were calculated using Excel (Microsoft, Redmond, Wash., USA).

MVD was assessed by counting the number of CD34-positive capillary, arteriolar or sinus lumen in five $1-\mathrm{mm}^{2}$ fields at $\times 100$ magnification and calculating the mean of these 5 fields.

Fibrosis was graded according to the European consensus on grading of bone marrow fibrosis [26].

\section{Statistical Analysis}

The data were statistically evaluated using the SPSS 15 statistical package and analyzed descriptively (descriptives, explore and crosstabs). Statistical comparisons were performed by MannWhitney $\mathrm{U}$ test for median values and by the independent $\mathrm{t}$ test to evaluate differences in clinical parameters between the different groups. Values of $\mathrm{p}<0.05$ were considered statistically significant. Pearson's test was performed to correlate the expression of pErk, pAkt, p70S6k and Bnip3 with MVD, and fibrosis grading with MVD.

In some cases bone marrow tissue was lost during pretreatment of the slides; for pErk we report 4 missing values, for pAkt 5, for p70S6k 20, for Bnip3 21 and for MVD 5 missing values. For the grading of myelofibrosis we report 2 missing values. 
Fig. 1. Examples of pErk, pAkt, Bnip3 and p70S6k staining in MPN patients and control patients. a pErk $(\mathrm{HE}, 1000 \times)$ staining in MPN patient. b pErk (HE, 650×) staining in control patient. c pAkt (HE, 630 $)$ staining in MPN patient. d pAkt (HE, $650 \times)$ staining in control patient. e Bnip3 $(\mathrm{HE}, 1000 \times)$ in MPN patient. $\mathbf{f}$ Bnip3 (HE, $650 \times)$ in control patient. g p70S6k (HE, $1000 \times)$ in MPN patient. h p70S6k (HE, $650 \times$ ) in control patient.
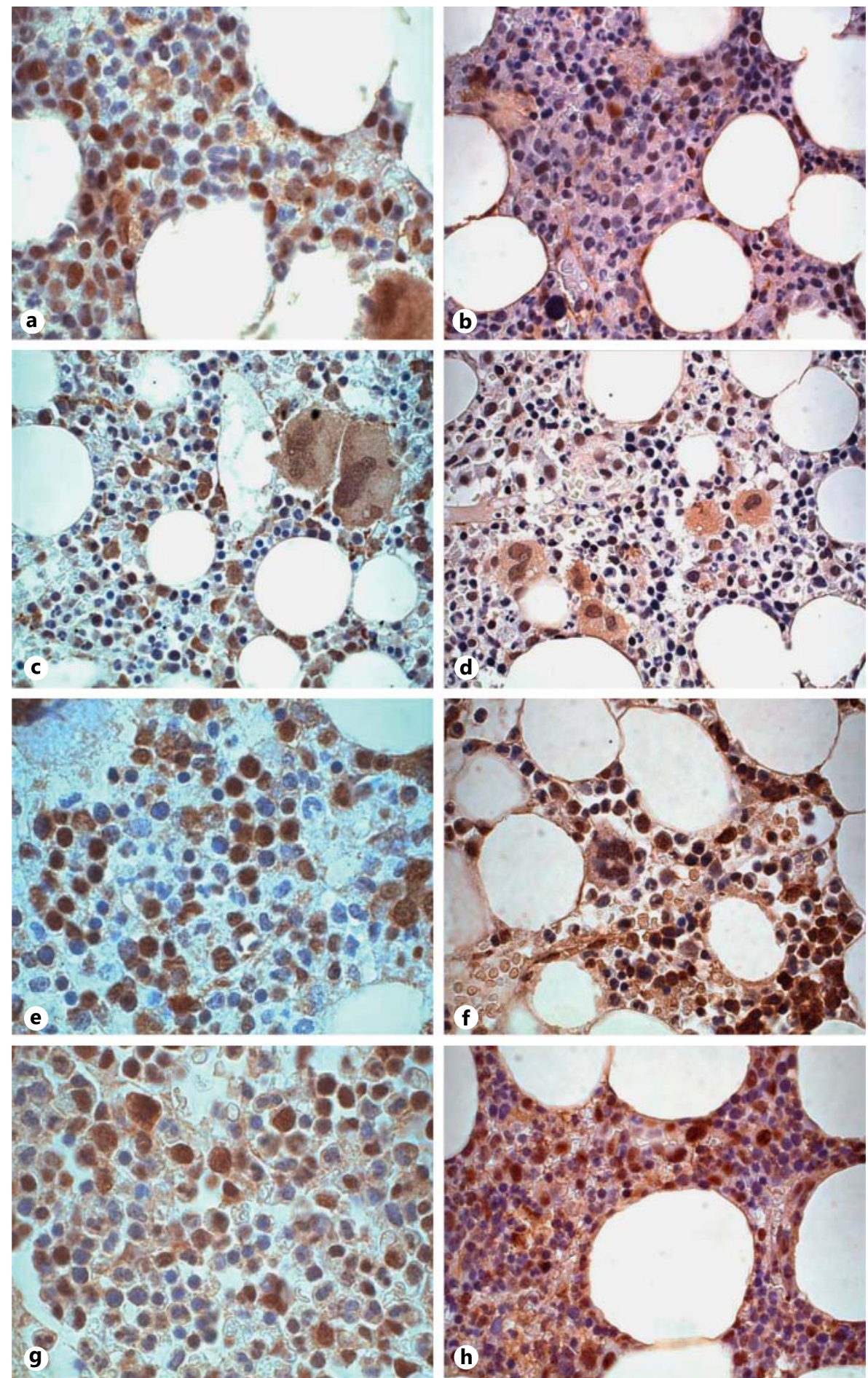

\section{Results}

The results of staining are summarized in tables 3-7. Qualitative microscopic evaluation of pErk showed nuclear expression predominantly in the erythroblasts and occasionally in endothelial cells and plasma cells. Granulopoiesis and myelopoiesis did not show any pErk expression. Compared to the control, pErk expression was significantly higher in the general bone marrow of ET patients $(p=0.013)$ and the total MPN group $(p=0.028)$. In 
Table 3. Percentage of positively stained megakaryocytes in ET, PV and PMF patients versus the control group

\begin{tabular}{|c|c|c|c|c|c|c|c|}
\hline $\begin{array}{l}\text { Positively stained } \\
\text { megakaryocytes }\end{array}$ & $\mathrm{ET}(\mathrm{n}=36)$ & $\mathrm{p}$ value & $\mathrm{PV}(\mathrm{n}=25)$ & $\mathrm{p}$ value & $\operatorname{PMF}(\mathrm{n}=45)$ & $\mathrm{p}$ value & $\begin{array}{l}\text { Control group } \\
(\mathrm{n}=36)\end{array}$ \\
\hline pErk & $80.13 \pm 26.67$ & 0.02 & $84.25 \pm 25.67$ & 0.01 & $75.61 \pm 30.92$ & 0.10 & $63.62 \pm 32.69$ \\
\hline Bnip3 & $97.04 \pm 6.27$ & 0.07 & $87.72 \pm 23.23$ & 0.80 & $83.00 \pm 29.67$ & 0.66 & $86.29 \pm 30.92$ \\
\hline p70S6k & $95.92 \pm 7.38$ & 0.12 & $86.79 \pm 22.70$ & 0.77 & $87.77 \pm 19.65$ & 0.87 & $88.63 \pm 24.58$ \\
\hline VEGF & $84.59 \pm 20.97$ & 0.57 & $79.32 \pm 26.00$ & 0.80 & $86.80 \pm 22.67$ & 0.35 & $81.13 \pm 27.67$ \\
\hline
\end{tabular}

Means \pm SD. $t$ test.

Table 4. Percent pErk, pAkt, Bnip3, p70S6k and MVD in ET, PV and PMF, all MPN and control patients in total bone marrow cells

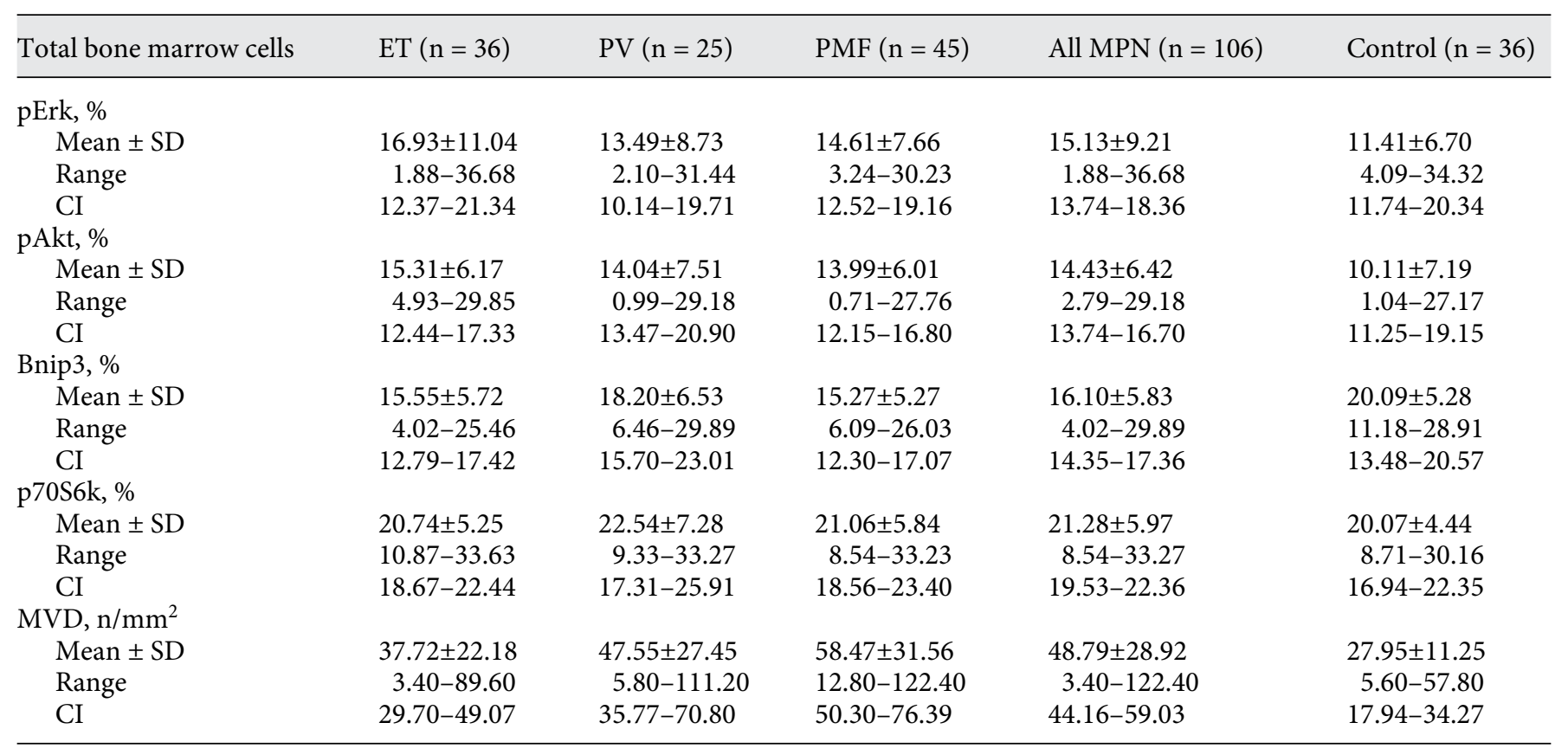

$\mathrm{CI}=$ Confidence interval. Percent positive nuclei per total nuclei counted are shown except for MVD.

megakaryocytes, pErk expression was significantly higher in ET $(\mathrm{p}=0.000), \mathrm{PV}(\mathrm{p}=0.000)$ and PMF patients $(\mathrm{p}=$ $0.000)$ and in the total MPN group $(\mathrm{p}=0.000)$ compared to the control group. As shown in table 2, there were significantly more stained megakaryocytes in the ET and PV group compared to the control group.

pAkt was expressed in the cytoplasm and nucleus of immature myeloid cells. Megakaryocytes showed cytoplasmic expression of pAkt. pAkt expression was significantly higher in megakaryocytes of ET $(\mathrm{p}=0.000), \mathrm{PV}$ $(\mathrm{p}=0.000)$ and PMF patients $(\mathrm{p}=0.000)$ and in the total MPN group ( $\mathrm{p}=0.000)$ compared to the control group.
The megakaryocytes of ET patients showed significantly higher pAkt expression compared to PV $(\mathrm{p}=0.035)$ and PMF $(\mathrm{p}=0.050)$ patients.

Bnip3 showed nuclear and cytoplasmic expression in myeloid cells. The megakaryocytes expressed Bnip 3 in the cytoplasm and the endothelial cells in the nuclei. The expression of Bnip3 in the general bone marrow was statistically significantly higher in the control group: $\mathrm{p}=0.003$ versus ET patients, $\mathrm{p}=0.001$ versus PMF patients and $p=0.001$ versus the total MPN group. However, megakaryocytes expressed Bnip3 significantly higher in ET $(\mathrm{p}=0.000)$, PV $(\mathrm{p}=0.000)$ and PMF pa- 
Table 5. Percent pErk, pAkt, Bnip3, p70S6k and MVD in JAK2-positive and wild-type JAK2 patients in total bone marrow cells

\begin{tabular}{lcc}
\hline Total bone marrow cells & JAK2 positive $(\mathrm{n}=56)$ & Wild-type JAK2 $(\mathrm{n}=24)$ \\
\hline pErk, $\%$ & & \\
Mean \pm SD & $17.10 \pm 9.89$ & $13.71 \pm 7.52$ \\
Range & $3.65-36.68$ & $1.88-25.79$ \\
CI & $13.58-19.41$ & $10.82-17.53$ \\
pAkt, \% & $14.82 \pm 6.40$ & $16.89 \pm 5.45$ \\
Mean \pm SD & $3.47-29.18$ & $8.35-23.30$ \\
Range & $13.03-16.71$ & $13.72-17.90$ \\
CI & $16.89 \pm 4.43$ & $17.84 \pm 5.25$ \\
Bnip3, $\%$ & $4.02-28.22$ & $7.21-26.03$ \\
Mean \pm SD & $15.49-18.65$ & $15.25-20.44$ \\
Range & & \\
CI & $22.74 \pm 5.73$ & $21.47 \pm 4.17$ \\
p70S6k, \% & $8.54-33.63$ & $13.76-27.47$ \\
Mean \pm SD & $21.21-24.46$ & $19.46-23.48$ \\
Range & $52.77 \pm 30.58$ & $49.01 \pm 25.98$ \\
CI & $3.60-122.40$ & $17.20-111.20$ \\
MVD, n $/ m m^{2}$ & $44.72-63.18$ & $40.64-65.24$ \\
Mean \pm SD & \\
Range & & \\
CI &
\end{tabular}

Percent positive nuclei per total nuclei counted are shown except for MVD.

Table 6. Absolute amount of positively stained megakaryocytes of pErk, pAkt, Bnip3 and p70S6k in ET, PV, PMF, all MPN and control patients

\begin{tabular}{|c|c|c|c|c|c|}
\hline $\begin{array}{l}\text { Absolute amount of } \\
\text { positive megakaryocytes }\end{array}$ & $\begin{array}{l}\text { ET } \\
(n=36)\end{array}$ & $\begin{array}{l}\text { PV } \\
(\mathrm{n}=25)\end{array}$ & $\begin{array}{l}\text { PMF } \\
(\mathrm{n}=45)\end{array}$ & $\begin{array}{l}\text { All MPN } \\
(\mathrm{n}=106)\end{array}$ & $\begin{array}{l}\text { Control } \\
(\mathrm{n}=36)\end{array}$ \\
\hline \multicolumn{6}{|l|}{ pErk } \\
\hline Mean \pm SD & $2.79 \pm 1.91$ & $2.24 \pm 1.32$ & $1.88 \pm 1.55$ & $2.29 \pm 1.67$ & $0.71 \pm 0.69$ \\
\hline Range & $0.00-7.00$ & $0.60-5.60$ & $0.00-5.20$ & $0.00-7.00$ & $0.00-3.40$ \\
\hline CI & $2.06-3.51$ & $1.62-2.86$ & $1.32-2.44$ & $1.93-2.66$ & $0.46-0.96$ \\
\hline \multicolumn{6}{|l|}{ pAkt } \\
\hline Mean \pm SD & $3.04 \pm 1.47$ & $2.25 \pm 1.71$ & $2.38 \pm 1.42$ & $2.59 \pm 1.53$ & $1.11 \pm 0.95$ \\
\hline Range & $0.80-7.60$ & $0.00-7.80$ & $0.40-5.80$ & $0.00-7.80$ & $0.00-4.00$ \\
\hline CI & $2.48-3.60$ & $1.45-3.05$ & $1.87-2.89$ & $2.25-2.92$ & $0.76-1.46$ \\
\hline \multicolumn{6}{|l|}{ Bnip3 } \\
\hline Mean \pm SD & $2.43 \pm 1.31$ & $1.85 \pm 1.19$ & $1.95 \pm 1.47$ & $2.10 \pm 1.35$ & $0.68 \pm 0.46$ \\
\hline Range & $0.20-5.40$ & $0.20-4.00$ & $0.00-5.20$ & $0.00-5.40$ & $0.00-1.60$ \\
\hline CI & $1.94-2.93$ & $1.29-2.40$ & $1.42-2.48$ & $1.80-2.40$ & $0.51-0.85$ \\
\hline \multicolumn{6}{|l|}{ p70S6k } \\
\hline Mean \pm SD & $2.85 \pm 1.24$ & $1.80 \pm 1.23$ & $1.96 \pm 1.27$ & $2.24 \pm 1.32$ & $0.97 \pm 0.65$ \\
\hline Range & $0.60-5.80$ & $0.00-5.80$ & $0.00-6.80$ & $0.00-6.80$ & $0.00-2.80$ \\
\hline $\mathrm{CI}$ & $2.38-3.32$ & $1.22-2.37$ & $1.50-2.41$ & $1.94-2.53$ & $0.73-1.21$ \\
\hline
\end{tabular}

tients $(\mathrm{p}=0.000)$ and in the total MPN group $(\mathrm{p}=0.000)$ compared to the control group. Bnip3 expression was also significantly higher in megakaryocytes of ET patients compared to megakaryocytes of $\mathrm{PV}$ patients $(\mathrm{p}=$ $0.019)$.
p70S6k was mainly expressed in immature (nuclear) and mature myeloid cell lines (nuclear and cytoplasmic). Megakaryocytes expressed p70S6k in the cytoplasm and in the nucleus. Adipocytes also expressed p70S6k. p70S6k expression was significantly increased in megakaryocytes of 


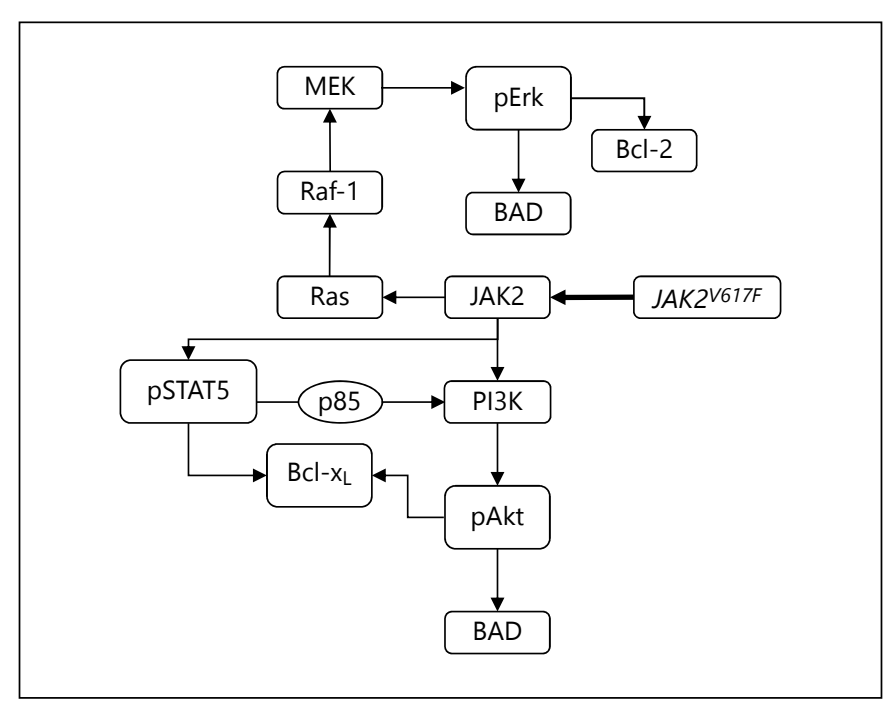

Fig. 2. Erk and PI3K-Akt signalling pathway.

Table 7. Absolute amount of positively stained megakaryocytes of pErk, pAkt, Bnip3 and p70S6k in JAK2-positive or wild-type JAK2 patients

\begin{tabular}{lll}
\hline $\begin{array}{l}\text { Absolute amount of } \\
\text { positive megakaryocytes }\end{array}$ & $\begin{array}{l}\text { JAK2 positive } \\
(\mathrm{n}=56)\end{array}$ & $\begin{array}{l}\text { Wild-type JAK2 } \\
(\mathrm{n}=24)\end{array}$ \\
\hline pErk & & \\
$\quad$ Mean \pm SD & $2.39 \pm 1.71$ & $1.42 \pm 1.50$ \\
$\quad$ Range & $0.00-6.60$ & $0.00-7.00$ \\
CI & $1.88-2.90$ & $1.00-1.85$ \\
pAkt & & \\
Mean \pm SD & $2.67 \pm 1.61$ & $1.84 \pm 1.61$ \\
Range & $0.60-7.80$ & $0.00-7.60$ \\
CI & $1.38-2.29$ & $1.38-2.29$ \\
Bnip3 & & \\
Mean \pm SD & $2.16 \pm 1.37$ & $1.31 \pm 1.13$ \\
Range & $0.00-5.40$ & $0.00-4.80$ \\
CI & $1.75-2.56$ & $0.99-1.63$ \\
p70S6k & & \\
Mean \pm SD & $2.30 \pm 1.46$ & $1.52 \pm 1.06$ \\
Range & $0.00-6.80$ & $0.00-5.00$ \\
CI & $1.86-2.73$ & $1.22-1.82$ \\
\hline CI = Confidence interval. & & \\
\hline
\end{tabular}

$\mathrm{ET}(\mathrm{p}=0.000), \mathrm{PV}(\mathrm{p}=0.000)$ and PMF patients $(\mathrm{p}=0.000)$ and in the total MPN group $(\mathrm{p}=0.000)$ compared to megakaryocytes of the control group. The megakaryocytes of ET patients showed significantly higher p70S6k expression compared PV $(\mathrm{p}=0.003)$ and PMF patients $(\mathrm{p}=0.008)$.

Concerning myelofibrosis grading and staining, we report statistically significantly higher p70S6k expression in

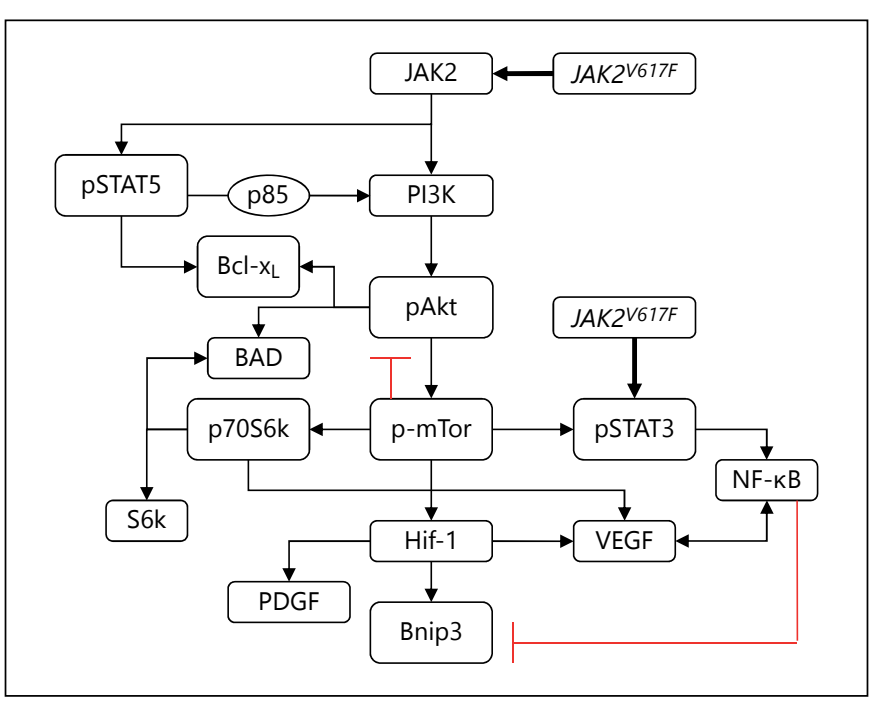

Fig. 3. Bnip3 and p70S6k signalling pathway.

the $\mathrm{mf} 0 / 1$ group $(\mathrm{p}=0.033)$ compared to the $\mathrm{mf} 2 / 3$ group. Regarding MVD, MVD expression was higher in the $\mathrm{mf} 2 / 3$ group $(\mathrm{p}=0.001)$ compared to the $\mathrm{mf} 0 / 1$ group. Pearson's correlation also showed a significant correlation of MVD with the grading of myelofibrosis $(\mathrm{p}=0.000)$.

\section{Discussion}

In this study, we examined the immunohistochemical expression of pErk, pAkt, Bnip3 and p70S6k in total bone marrow cells and megakaryocytes of ET, PV, PMF and control patients along with the MVD.

Activated Erk activates BAD, an apoptosis activator, and $\mathrm{Bcl}-2$, an apoptosis inhibitor $[27,28]$. The net result of Erk phosphorylation is an overall inhibition of apoptosis. In our study, pErk expression was increased in the bone marrow of MPN patients, which may explain the increased bone marrow cellularity seen in MPN patients. Although Erk was constitutivelyactivated by the JAK2 ${ }^{\mathrm{V} 617 \mathrm{~F}}$ mutation, we failed to show a significant pErk increase in $J A K 2^{V 617 F}$-positive patients. This might be due to the relatively high number of patients with an unknown JAK2 status in our study. The overall higher pErk expression in megakaryocytes, which was mainly noted in ET patients but also PV and PMF patients and in the total MPN group in our study, might indicate a major role for megakaryocytes in MPN pathogenesis, especially in ET patients. However, in ET patients, it might also be a result of the disease itself, while there was a significantly higher 
amount of stained megakaryocytes in ET patients compared to the control group.

Akt is phosphorylated by activated PI3K, which in turn can be phosphorylated by pSTAT5 and the JAK2 $2^{\text {V617F }}$ mutation (fig. 2). The downstream effector of pAkt is the apoptosis inhibitor of megakaryocytes, $\mathrm{Bcl}-\mathrm{x}_{\mathrm{L}}[5,29-33]$. Megakaryocytes of ET, PV and PMF patients and the total MPN group showed higher pAkt expression compared to the megakaryocytes of control patients in our study, with the highest expression noted in ET patients. This suggests a role for pAkt in the pathological increase in megakaryocytes seen in the bone marrow of MPN patients leading to an increase in platelets in the peripheral blood. However, our results could not confirm the increased pAkt expression in $J A K 2^{V 617 F}$-positive patients found in several previous studies $[34,35]$ probably due to the relatively high number of patients with an unknown JAK2 status.

Bnip3 is a pro-apoptotic protein which is activated under hypoxic conditions by Hif-1a (fig. 3) [24]. The lower Bnip3 expression in the total group of MPN patients in our study might indicate that the increased bone marrow cellularity is also a result of decreased apoptosis and not only due to proliferative activity. A discrepancy seems to exist between our results of Bnip3 expression in total bone marrow cells and the Bnip3 expression in megakaryocytes of MPN patients. However, it might also refer to the protective role against bone marrow apoptosis; Bnip3 might contribute to the increased cellularity in total bone marrow cells.

Concerning the activation of p70S6k, the formation of a complex between the regulatory subunit of PI3K (p85) and $m$ Tor is required [21] and is therefore in line with the higher pAkt expression in megakaryocytes of MPN patients in our study. Activated p70S6k phosphorylates $\mathrm{BAD}$ resulting in inactivation of $\mathrm{BAD}$ and consequently inhibition of apoptosis (fig. 3) [36]. The increased expres- sion of p70S6k in megakaryocytes of MPN patients might indicate an inhibition of megakaryocyte apoptosis via p70S6k.

More studies were done to assess MVD in MPN patients: all show higher MVD in PMF patients compared to ET and PV patients and higher MVD in post-ET myelofibrosis and post-PV myelofibrosis compared to ET and $\mathrm{PV}$, which indicates that angiogenesis is primarily involved in later stages of the disease [37-41]. We found a correlation between MVD and fibrosis, which is line with the study by Boveri et al. [38], who found that MVD increased with the grade of fibrosis.

Higher p70S6k expression in the $\mathrm{mf} 0 / 1$ group compared to the $\mathrm{mf} 2 / 3$ group indicates a declining p70S6k expression with increasing myelofibrosis. This might also explain why we did not find a significant difference in p70S6k expression in bone marrow cells between MPN patients and control patients, while a higher percentage of patients in our study belonged to the $\mathrm{mf} 2 / 3$ group.

In conclusion, the increased cellularity seen in MPN bone marrow might be influenced by the increased expression and anti-apoptotic mechanism of the pErk and pAkt pathways and a decreased expression of the proapoptotic protein Bnip3 in bone marrow cells in general. The increased amount of megakaryocytes seen in MPN might be due to the increased pAkt and p70S6k expression. Further, our results also suggest an important pathogenetic role for megakaryocytes in the pathogenesis of MPN patients, mainly in ET patients, as the anti-apoptotic pErk, pAkt, p70S6k and Bnip3 expression was higher in MPN megakaryocytes, mainly in ET patients, compared to the controls. Further, the increased MVD expression in patients with myelofibrosis suggests an important role of angiogenesis in the development of myelofibrosis and is therefore a potential therapeutic target in MPN patients with myelofibrosis.

\section{References}

1 Vardiman JW, Harris NL, Brunning RD: The World Health Organization (WHO) classification of the myeloid neoplasms. Blood 2002; 100:2292-2302.

$>2$ Campbell PJ, Green AR: The myeloproliferative disorders. N Engl J Med 2006;355:2452-2466.

3 Murray J: Myeloproliferative disorders. Clin Med 2005;5:328-332.

4 Baxter EJ, Scott LM, Campbell PJ, et al: Acquired mutation of the tyrosine kinase JAK2 in human myeloproliferative disorders. Lancet 2005;365:1054-1061.
5 James C, Ugo V, Le Couedic JP, et al: A unique clonal JAK2 mutation leading to constitutive signalling causes polycythaemia vera. Nature 2005;434:1144-1148.

6 Kralovics R, Passamonti F, Buser AS, et al: A gain-of-function mutation of JAK2 in myeloproliferative disorders. N Engl J Med 2005; 352:1779-1790.

7 Levine RL, Wadleigh M, Cools J, et al: Activating mutation in the tyrosine kinase JAK2 in polycythemia vera, essential thrombocythemia, and myeloid metaplasia with myelofibrosis. Cancer Cell 2005;7: 387-397.

8 Dhillon AS, Hagan S, Rath O, et al: MAP kinase signalling pathways in cancer. Oncogene 2007; 26:3279-3290.

9 Kim EK, Choi EJ: Pathological roles of MAPK signaling pathways in human diseases. Biochim Biophys Acta 2010;1802:396-405.

10 Boulton TG, Yancopoulos GD, Gregory JS, et al: An insulin-stimulated protein kinase similar to yeast kinases involved in cell cycle control. Science 1990;249:64-76. 
11 Racke FK, Lewandowska K, Goueli S, et al: Sustained activation of the extracellular signal-regulated kinase/mitogen-activated protein kinase pathway is required for megakaryocytic differentiation of K562 cells. J Biol Chem 1997;272:23366-23370.

-12 Rouyez MC, Boucheron C, Gisselbrecht S, et al: Control of thrombopoietin-induced megakaryocytic differentiation by the mitogen-activated protein kinase pathway. Mol Cell Biol 1997;17:4991-5000.

$\checkmark 13$ Whalen AM, Galasinski SC, Shapiro PS, et al: Megakaryocytic differentiation induced by constitutive activation of mitogen-activated protein kinase kinase. Mol Cell Biol 1997;17: 1947-1958.

14 Yao R, Cooper GM: Growth factor-dependent survival of rodent fibroblasts requires phosphatidylinositol 3-kinase but is independent of pp70S6k activity. Oncogene 1996;13: 343-351.

15 Dudek H, Datta SR, Franke TF, et al: Regulation of neuronal survival by the serine-threonine protein kinase Akt. Science 1997;275: 661-665.

16 Kauffmann-Zeh A, Rodriquez-Viciana P, Ulrich E, et al: Suppression of c-Myc-induced apoptosis by Ras signalling through $\mathrm{PI}(3) \mathrm{K}$ and PKB. Nature 1997;385:544-548.

17 Kennedy SG, Wagner AJ, Conzen SD, et al: The PI 3-kinase/Akt signaling pathway delivers an anti-apoptotic signal. Genes Dev 1997; 11:701-713.

18 Kulik G, Klippel A, Weber MJ: Antiapoptotic signalling by the insulin-like growth factor I receptor, phosphatidylinositol 3-kinase, and Akt. Mol Cell Biol 1997;17:1595-1606.

19 Bakin AV, Tomlinson AK, Bhowmick NA, et al: Phosphatidylinositol 3-kinase function is required for transforming growth factor betamediated epithelial to mesenchymal transition and cell migration. J Biol Chem 2000;275: 36803-36810.

20 Yee KW, Zeng Z, Konopleva M, et al: Phase I/ II study of the mammalian target of rapamycin inhibitor everolimus (RAD001) in patients with relapsed or refractory hematologic malignancies. Clin Cancer Res 2006;12:51655173 .
21 Gonzalez-Garcia A, Garrido E, Hernandez C, et al: A new role for the $\mathrm{p} 85$-phosphatidylinositol 3-kinase regulatory subunit linking FRAP to p70 S6 kinase activation. J Biol Chem 2002;277:1500-1508.

22 Boyd JM, Malstrom S, Subramanian T: Ade novirus E1B $19 \mathrm{kDa}$ and $\mathrm{Bcl}-2$ proteins interact with a common set of cellular proteins. Cell 1994;79:1121.

23 Chen G, Ray R, Dubik D, et al: The E1B 19K/ $\mathrm{Bcl}$-2-binding protein Nip3 is a dimeric mitochondrial protein that activates apoptosis. J Exp Med 1997;186:1975-1983.

24 Giatromanolaki A, Koukourakis MI, Sowter $\mathrm{HM}$, et al: BNIP3 expression is linked with hypoxia-regulated protein expression and with poor prognosis in non-small cell lung cancer. Clin Cancer Res 2004;10:5566-5571.

25 Swerdlow SH, Campo E, Harris NL, et al: WHO Classification of Tumours of Haematopoietic and Lymphoid Tissues, Fourth Edition. WHO Classification of Tumours, Volume 2. IARC WHO Classification of Tumours, No 2. Geneva, WHO, 2008.

26 Thiele J, Kvasnicka HM, Facchetti F, et al: European consensus on grading bone marrow fibrosis and assessment of cellularity. Haematologica 2005;90:1128-1132.

-27 Datta SR, Brunet A, Greenberg ME: Cellular survival: a play in three Akts. Genes Dev 1999; 13:2905-2927.

28 Datta SR, Dudek H, Tao X, et al: Akt phosphorylation of BAD couples survival signals to the cell-intrinsic death machinery. Cell 1997;91:231-241.

29 Levine RL, Pardanani A, Tefferi A, et al: Role of JAK2 in the pathogenesis and therapy of myeloproliferative disorders. Nat Rev Cancer 2007;7:673-683.

30 Kirito K, Watanabe T, Sawada K, et al: Thrombopoietin regulates $\mathrm{Bcl}-\mathrm{xL}$ gene expression through Stat5 and phosphatidylinositol 3-kinase activation pathways. J Biol Chem 2002; 277: 8329-8337.
31 Nyga R, Pecquet C, Harir N, et al: Activated STAT5 proteins induce activation of the PI3kinase/Akt and Ras/MAPK pathways via the Gab2 scaffolding adapter. Biochem J 2005; 390(Pt 1):359-366.

32 Schwaller J, Parganas E, Wang D, et al: Stat5 is essential for the myelo- and lymphoproliferative disease induced by TEL/JAK2. Mol Cell 2000;6:693-704.

33 Liu FT, Rabinovich GA: Galectins as modulators of tumour progression. Nat Rev Cancer 2005;5:29-41.

34 Grimwade LF, Happerfield L, Tristram C, et al: Phospho-STAT5 and phospho-Akt expression in chronic myeloproliferative neoplasms. Br J Haematol 2009;147:495-506.

35 Kamishimoto J, Taqo K, Kasahara T, et al: Akt activation through the phosphorylation of erythropoietin receptor at tyrosine 479 is required for myeloproliferative disorder-associated JAK2 V617F mutant-induced cellular transformation. Cell Signal 2011;23:849-856.

36 Harris AL: Hypoxia - a key regulatory factor in tumour growth. Nat Rev Cancer 2002;2: $38-47$.

37 Arora B, Ho CL, Hoyer JD, et al: Bone marrow angiogenesis and its clinical correlates in myelofibrosis with myeloid metaplasia. Haematologica 2004;89:1454-1458.

38 Boveri E, Passamonti F, Rumi E, et al: Bone marrow microvessel density in chronic myeloproliferative disorders: a study of $115 \mathrm{pa}$ tients with clinicopathological and molecular correlations. Br J Haematol 2008;140:162168

39 Panteli K, Zagorianakou N, Bai M, et al: Angiogenesis in chronic myeloproliferative diseases detected by CD34 expression. Eur J Haematol 2004;72:410-415.

40 Steurer M, Zoller H, Augustin F, et al: Increased angiogenesis in chronic idiopathic myelofibrosis: vascular endothelial growth factor as a prominent angiogenic factor. Hum Pathol 2007;38:1057-1064.

$\checkmark 41$ Gianelli U, Vener C, Raviele PR, et al: VEGF expression correlates with microvessel density in Philadelphia chromosome-negative chronic myeloproliferative disorders. Am J Clin Pathol 2007;128:966-973. 